\title{
A business case modelling framework for smart multi- energy districts
}

DOI:

10.1049/cp.2016.0768

\section{Document Version}

Accepted author manuscript

Link to publication record in Manchester Research Explorer

\section{Citation for published version (APA):}

Good, N., Martinez Cesena, E. A., Liu, X., \& Mancarella, P. (2017). A business case modelling framework for smart multi-energy districts. In CIRED Workshop 2016 https://doi.org/10.1049/cp.2016.0768

\section{Published in:}

CIRED Workshop 2016

\section{Citing this paper}

Please note that where the full-text provided on Manchester Research Explorer is the Author Accepted Manuscript or Proof version this may differ from the final Published version. If citing, it is advised that you check and use the publisher's definitive version.

\section{General rights}

Copyright and moral rights for the publications made accessible in the Research Explorer are retained by the authors and/or other copyright owners and it is a condition of accessing publications that users recognise and abide by the legal requirements associated with these rights.

\section{Takedown policy}

If you believe that this document breaches copyright please refer to the University of Manchester's Takedown Procedures [http://man.ac.uk/04Y6Bo] or contact uml.scholarlycommunications@manchester.ac.uk providing relevant details, so we can investigate your claim.

\section{OPEN ACCESS}




\title{
A BUSINESS CASE MODELLING FRAMEWORK FOR SMART MULTI-ENERGY DISTRICTS
}

\author{
Nicholas GOOD \\ Eduardo A. MARTÍNEZ CESEÑA \\ Xuezhi LIU \\ Pierluigi MANCARELLA \\ University of Manchester - UK \\ \{nicholas.good, eduardo.martinezcesena, xuezhi.liu, p.mancarella\}@manchester.ac.uk
}

\begin{abstract}
The potential energy, environmental, technical and economic benefits that might arise from multi-energy systems are increasing interest in smart districts. However, in a liberalised market, it is essential to develop a relevant attractive business case. This paper presents a holistic techno-economic framework that couples building/district, multi-network and business case assessment models for the development of robust business cases for smart multi-energy districts. The framework is demonstrated within the context of the FP7 DIMMER project on a real UK case study at the University of Manchester.
\end{abstract}

\section{INTRODUCTION}

Globally, energy systems are facing threats to their reliable and economic operation from the 'energy trilemma' of sustainability, affordability and security [1]. Cornerstones of adaptation policies have been policies to increase efficiency of energy systems, and to increase penetration of low-carbon/renewable electricity, and, lately, heat and transport. In this context, multi-energy systems, at various scales, have been identified as interesting means to increase general system efficiency and performance with respect to multiple metrics (e.g., cost, emissions, reliability) [2]. Additionally, such multi-energy systems can contribute to internal and system objectives (relating to the energy trilemma) by operating flexibly, and explicitly selling flexibility on power system markets (e.g., reserve or capacity markets). Districts may be considered particularly interesting as providers of flexibility, for several reasons. Firstly, they can have substantial flexibility [3], [4], which may be exploited relatively cheaply. Secondly, advances in enabling ICT, and in liberalisation of various energy system markets, which facilitate the integration of demand-side resources, are making exploitation of flexibility from districts ever more feasible [5]. Thirdly, the ubiquity of districts, and their location (generally) on distribution networks, where there may be no other alternative flexibility resources, means that there may be great demand for flexibility from smart districts.

However, districts have several features which can greatly complicate their modelling and assessment. Firstly, there is the complexity relating to energy transfer, storage and consumption within the district buildings. Buildings are intrinsically multi-energy, as energy (typically electricity or gas) is converted to provide heat/cooling, and other energy services. In particular, understanding how heat/cooling is distributed around buildings, and how the thermal inertia of heating systems and buildings effects demand and comfort is not a trivial task [6]. Further, exploration of various options for energy conversion, storage and distribution requires detailed physical models [7]. Secondly, there is further complexity given the physical interactions between buildings. This requires the capability to model relevant energy networks (i.e., electricity, gas and heat) and their interactions [8]. Lastly, given that modern energy systems are generally liberalised, it is required to quantify a business case for smart districts. At a fundamental level, this requires methods for identifying the exchanges of commodities/cash which characterise energy systems [9], and should include the ability to model both physical and virtual (i.e., of physically distributed premises) aggregation [10].

Whilst there has been development on the relevant physical and commercial challenges of assessment, a framework bringing together all the components necessary to conduct business case assessment of smart multi-energy districts is missing. To address this gap, this paper presents a business case modelling framework for such districts. The framework is made up of a physical building simulation model, a multi-energy network model, and a business case assessment model, as described below, and is illustrated on a real UK case study developed within the context of the FP7 DIMMER project, which aims at developing an information platform to facilitate energy efficiency improvements via actuation (e.g., investments in renewable energy technologies) and optimal use of multi-energy vectors (e.g., by automating and optimizing the operation of relevant infrastructure).

\section{MODELLING FRAMEWORK}

The modelling framework (see Fig. 1) is made up of several modules, which are discussed in detail below.

\section{Building physical model}

Accurate assessment of business cases for smart multienergy districts requires sophisticated building models to accurately capture the effects of several aspects of building energy behaviour. As demonstrated in Fig. 2 which shows the structure of an updated version of the high-resolution domestic demand model presented in [7], building energy profiles (typically gas and electricity) are dependent on demand for energy 


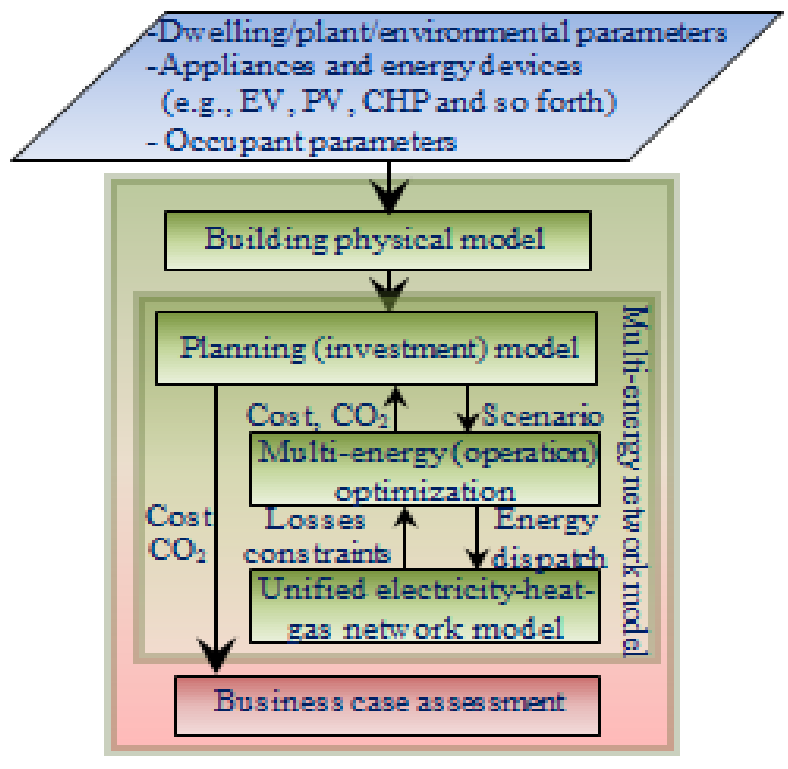

Fig. 1: Techno-economic modelling framework

services, and the devices and energy vectors used to provide those energy services. Another key aspect of building energy behaviour is that energy demand (and production, from distributed generation) is dependent on multiple factors. These include device characteristics (e.g., efficiency and rated power), environmental parameters (e.g., solar irradiance and temperature), user parameters (e.g., building set temperature and occupancy/activity), and heating system thermal inertia (e.g., heat emitter size). Identifying and isolating these parameters allows for parametric studies to be undertaken. The structure of the model also enables the coincidence of demand for different energy services (many of which share determinants), and the interaction between energy services (e.g., heat gain from cooking affects the space heating) model to be captured.

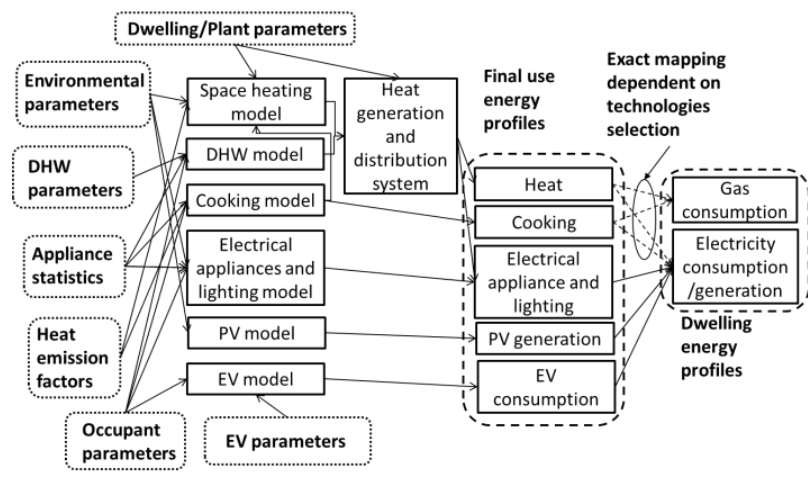

Fig. 2: Building energy model structure

\section{Multi-energy network models}

The multi-energy network model brings together optimisation and network analysis engines to optimally meet the energy requirements of the district specified by the physical model and a relevant business case. More specifically, an investment planning model coupled with a multi-energy flow optimisation engine [11] is used to optimally dispatch energy infrastructure (e.g., gas boilers, electric heat pump - EHP - and gas combined heat and power - CHP - boilers defined in a scenario) to meet energy demand while maximising benefits from a business case (e.g., wholesale costs minimisation). The optimisation engine is interfaced with an integrated electricity-heat-gas network simulation engine [8], which provides relevant losses and network limits to update the energy dispatch. Finally, the planning model identifies the optimal infrastructure to be deployed and expected costs and emissions.

\section{Business case assessment}

The business case of any district intervention depends on the energy prices, incentives, and other costs, the district is subject to. These price signals can be cast as exchanges, usefully describing the energy system commercial map [12]. By identifying individual price signals, the effect of an intervention on each cash flow, and hence each actor, can be identified. Further, this differentiation enable price components to be applied at the appropriate level, i.e., at the 'commercial' level for energy, at the grid connection point for grid fees, and at the premises level for taxes [10]. This differentiation allows for consideration of how commercial (virtual) aggregation, or adoption of a private wire network (physical aggregation) affects costs (as diversity within the aggregation changes net imports/exports).

In addition, in this work the role of retailer and aggregator are combined with that of the consumer, in the District actor (see [12] for further details). This leaves open the question of the nature of relationships between component actors, and allows, for example, for market prices to be passed directly to the consumer (with control of district resources remaining with the consumer), or arrangements similar to those of an energy service company where a $3^{\text {rd }}$ party controls district resources, to be provide energy services to contracted standards.

\section{CASE STUDY}

The proposed modelling framework is demonstrated with a real UK multi-energy district. The district comprises 17 buildings owned by The University of Manchester and connected to the same electricity distribution and gas networks. 15 of these buildings are also connected to the same heat network. The annual (2014) aggregated electricity and heat demand of the district are $11 \mathrm{GWhe}(2.5 \mathrm{MWe}$ peak) and 9.6 GWhth (14 MWth peak).

Currently, these buildings meet their energy demands 
through imports from the electricity grid, and heat production from central gas boilers or small building level gas boilers (for buildings not connected to the heat network). However, due to political reasons and environmental targets, the university is considering installing energy efficient technologies such as PV, CHP and EHP. Accordingly, and considering the environmental targets set by the university [13], the investment planning model recommends an investment of $2.9 \mathrm{M} £$ for the installation of $1935 \mathrm{kWe}$ of PV capacity, $1100 \mathrm{kWth}$ of EHP capacity and $250 \mathrm{kWe}$ of CHP capacity throughout the district. For the sake of simplicity and to focus this study on operational value, further results and discussion on investments is not included.

The district is subject to various energy, use-of-system (UoS) and tax charges. Grid electricity import is subject to wholesale import prices, electricity distribution UoS (EDUoS), electricity transmission UoS (ETUoS), balancing services UoS (BSUoS) charges, and valueadded-tax and environmental and social obligations (ESO). Meanwhile electricity export receives only the wholesale electricity export price [10]. Similarly, gas import is subject to gas wholesale prices, gas distribution and transmission UoS charges, and tax and ESO.

With respect to emissions, the gas emission factor is set at $190 \mathrm{kgCO}_{2} / \mathrm{MWh}$, whereas the electricity grid emissions are based on the split of grid 2013 UK electricity generation by type, the $\mathrm{CO}_{2}$ emission rate of each generator, considering $11 \%$ network losses (i.e., $442 \mathrm{kgCO}_{2} / \mathrm{MWh}$ on average).

The proposed modelling framework is used to simulate and assess the following four business cases:

1. Case 1 (baseline): All controllable energy infrastructure is assumed to operate in traditional heat following mode.

2. Case 2 (energy costs reduction): All controllable energy infrastructure is optimally dispatched with the aim of minimising energy wholesale prices.

3. Case 3 (network stress reduction): The energy flows within the district are optimised to minimise energy distribution charges.

4. Case 4 (all signals): The operation of controllable devices is optimised with the aim of minimising costs from all price signals, including wholesale prices, distribution charges, and also transmission, balancing services and tax charges.

It is important to note that, in order to properly model energy flows throughout the networks, the energy profiles of all other buildings connected to the different networks ( 22 buildings in addition to the 17 buildings already considered) were simulated. However, the costs, carbon and business implications associated with these additional 22 buildings are not explored in this work.

\section{Results}

Results in Fig. 3 present annual change in energy and emissions for cases 2-4 compared to case 1 . It can be seen that electricity import decrease and gas imports increase compared to the base case in all cases. This is due to comparatively low gas prices (including energy and DUoS charges) motivating a shift in heat production away from the EHP, to the gas fired CHP (which is also able to produce electricity, further reducing expensive electricity import) and gas boiler. This results in a net reduction in $\mathrm{CO}_{2}$ emissions, as increases in local emissions from gas fired heat generators are offset by reduced grid $\mathrm{CO}_{2}$ emissions

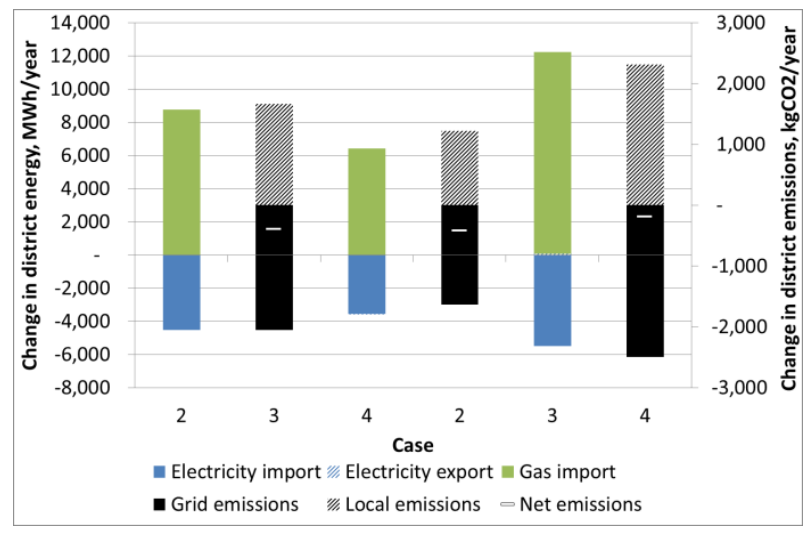

Fig. 3: Change in district energy/emissions, on case 1

Fig. 4 shows the change in district cash flow, compared to case 1, for each case. Electricity-related revenue increases as electricity consumption is avoided, whilst gas-related revenue decreases as gas consumption increases. Whilst the net effect is broadly similar across the cases, inspection reveals that energy revenue is greater in case 2 compared to case 3 , and DUoS revenue is greater in case 3 compared to case 2 . This shows the differing operation that each objective motivates, as energy and DUoS price signals do not align (see [10]).

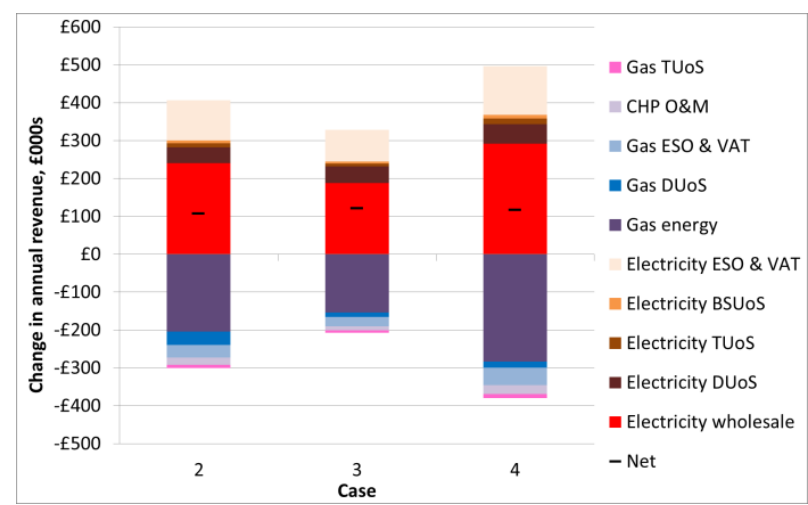

Fig. 4: Change in district cash flows, on case 1 
Fig. 5 shows the impact that case 4 can have of the business of different actors. The electricity producer is shown to be the biggest loser here, as the district reduces grid import. More importantly, the government and EDNO, which are key enablers for the business case of the district, also lose revenue. This is a vital insight offered by the proposed approach, as it highlights that financial arrangements and/or regulatory changes may be required for key actors (particularly the EDNO) to facilitate the business case of the smart district.

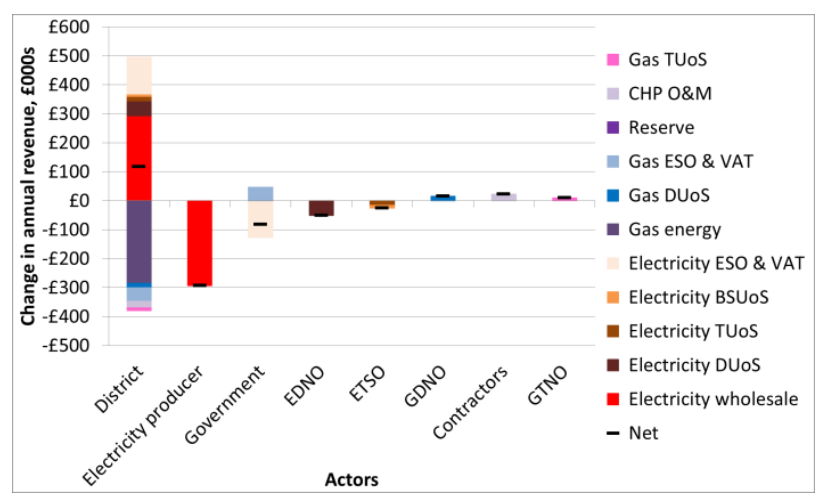

Fig. 5: Change in cash flow by actor, case 4 on case 1

\section{CONCLUSION}

This paper has introduced a new business case modelling framework, for smart multi-energy districts. The framework is made up of a high-resolution building physical model, to capture building thermal inertia and multi-energy demand, a multi-energy network model, which optimally dispatches energy conversion plant considering multi-energy network constraints, and a business case assessment, which identifies cash flows, by actor, by price component.

Demonstration of the framework on a real UK case study demonstrates the framework's potential to quantify energy, emissions and cash flows resulting from various business cases. Produced results demonstrate how the framework can be used to inform market and regulatory enablers, to facilitate business cases from smart, multi-energy districts.

Future work, within the DIMMER project and the newly commenced SEAF project, will consider the implications of smart district exploitation for investment and sharing of benefits between the district and thirdparty facilitators.

\section{ACKNOWLEDGEMENT}

This work was developed with the contribution and within the scope of the FP7 DIMMER and H2020 SEAF projects (ref nos. 609084/ 696023) supported by the EC, which the authors would like to acknowledge. The DIMMER project will develop an information platform to facilitate district and building level multienergy management with the aim of minimising capital costs and emissions. The SEAF project aims to develop standard assessment tools for small-medium sustainable energy projects, for investors and contractors, to lower market barriers for such projects

\section{REFERENCES}

[1] World Energy Council, "World Energy Trilemma Priority actions on climate change and how to balance the trilemma," 2015 .

[2] P. Mancarella, "MES (multi-energy systems): An overview of concepts and evaluation models," Energy, vol. 65, pp. 117, Nov. 2014

[3] T. Capuder and P. Mancarella, "Techno-economic and environmental modelling and optimization of flexible distributed multi-generation options," Energy, vol. 71, pp. 516-533, Jul. 2014.

[4] E. A. Martínez-Ceseña, N. Good, and P. Mancarella, "Electrical network capacity support from demand side response: Techno-economic assessment of potential business cases for small commercial and residential endusers," Energy Policy, vol. 82, pp. 222-232, Jul. 2015.

[5] N. Good, K. A. Ellis, and P. Mancarella, "Demand Response and the Smart Grid: Review, Analysis and Classification of Socio-Techno-Economic Barriers and Enablers," Renew. Sustain. Energy Rev., Submitted.

[6] N. Good, E. Karangelos, A. Navarro-Espinosa, and P. Mancarella, "Optimization under uncertainty of thermal storage based flexible demand response with quantification of residential users' discomfort," IEEE Trans. Smart Grid, vol. 6, no. 5, pp. 2333-2342, Sep. 2015.

[7] N. Good, L. Zhang, A. Navarro-Espinosa, and P. Mancarella, "High resolution modelling of multi-energy domestic demand profiles," Appl. Energy, vol. 137, pp. 193-210, Jan. 2015.

[8] X. Liu and P. Mancarella, "Modelling, assessment and Sankey diagrams of integrated electricity-heat-gas networks in multi-vector district energy systems," Appl. Energy, 2015

[9] N. Good, E. A. Martínez-Ceseña, C. Heltorp, and P. Mancarella, "Cost benefit analysis modelling of demand response business cases for smart energy districts," Energy Policy, Submitted.

[10] N. Good, E. A. Martínez-Ceseña, L. Zhang, and P. Mancarella, "Techno-Economic and Business Case Assessment of Low Carbon Technologies in Distributed Multi-Energy Systems," Appl. Energy, vol. In Press, 2015.

[11] E. A. Martínez-Ceseña, T. Capuder, and P. Mancarella, "Flexible Distributed Multienergy Generation System Expansion Planning Under Uncertainty," IEEE Trans. Smart Grid, vol. In Press, no. 1, pp. 348-357, Jan. 2015.

[12] E. A. Martínez-Ceseña, N. Good, and P. Mancarella, "Mapping for multi-form flows in smart multi-energy districts to facilitate new business cases," in Sustainable Places, 2014.

[13] The University of Manchester Directorate of Estates and Facilities, "Carbon (The University of Manchester)." [Online]. Available: http://www.estates.manchester.ac.uk/services/es/carbon/. [Accessed: 02-Mar-2016]. 